Jul 1st, 12:00 AM

\title{
Combining Dynamic Economic Analysis and Environmental Impact Modelling: Addressing Uncertainty and Complexity of Agricultural Development
}

Heikki Lehtonen

Ilona Bärlund

Sirkka Tattari

Mikael Hilden

Follow this and additional works at: https://scholarsarchive.byu.edu/iemssconference

Lehtonen, Heikki; Bärlund, Ilona; Tattari, Sirkka; and Hilden, Mikael, "Combining Dynamic Economic Analysis and Environmental Impact Modelling: Addressing Uncertainty and Complexity of Agricultural Development" (2004). International Congress on Environmental Modelling and Software. 85.

https://scholarsarchive.byu.edu/iemssconference/2004/all/85

This Event is brought to you for free and open access by the Civil and Environmental Engineering at BYU ScholarsArchive. It has been accepted for inclusion in International Congress on Environmental Modelling and Software by an authorized administrator of BYU ScholarsArchive. For more information, please contact scholarsarchive@byu.edu, ellen_amatangelo@byu.edu. 


\title{
Combining Dynamic Economic Analysis and Environ- mental Impact Modelling: Addressing Uncertainty and Complexity of Agricultural Development
}

\author{
$\underline{\text { Heikki Lehtonen }}^{\mathrm{a}}$, Ilona Bärlund ${ }^{\mathrm{b}}$, Sirkka Tattari $^{\mathrm{b}}$ and Mikael Hilden $^{\mathrm{b}}$ \\ ${ }^{a}$ MTT Economic Research, Agrifood Research Finland, Luutnantintie 13, FIN-00410 Helsinki, Finland \\ e-mail: heikki.lehtonen@mtt.fi \\ ${ }^{b}$ Finnish Environment Institute P.O.Box 140, FIN-00251 Helsinki, Finland
}

\begin{abstract}
In this study the impacts of different agricultural policies on agricultural production and nutrient leaching from agricultural lands are evaluated using the economic DREMFIA agricultural sector model and a field scale nutrient transport model ICECREAM. DREMFIA includes an evolutionary scheme of technology diffusion which considers farm investments, evolving farm size structure and technological change explicitly. The technology diffusion model allows self-inforcing patterns of technical change driven by the spread of information and farmers' knowledge related to different technological alternatives. Hence the long-term changes in agriculture due to policy changes may be essentially larger than those predicted by traditional static equilibrium models. Larger potential for changes in production provides a larger perspective for evaluation of environmental impacts. The environmental effects are studied using the field scale nutrient transport model ICECREAM, based on the land use changes predicted by the DREMFIA model. The modelled variables are nitrogen and phosphorus losses in surface runoff and percolation. Eutrophication of surface waters is the considered environmental effect. In this paper the modelling strategy will be presented and highlighted using two case study catchments with varying environmental conditions and land use.
\end{abstract}

Keywords: agricultural policy; economic modelling; technical change; eutrophication; nutrient leaching modelling

\section{INTRODUCTION}

Water quality, influenced by agricultural activities and policies, has been of great public interest and part of agricultural policy debate in Finland. For this reason, both long-term economic viability of agriculture, and nutrient leaching and water quality, are under focus in this paper.

Dynamic Regional Sector Model of Finnish Agriculture DREMFIA [Lehtonen 2001, 2004], which simulates economically rational production decisions, is used in this study in order to evaluate the likely impact of agricultural policy change on agricultural production. The model includes endogenous sector level investments which are important when evaluating long-term impacts of agricultural policy. Endogenous sector level investments, however, have been relatively rare in agricultural sector models [Heckelei et. al. 2001].
Investments, while affecting technical change and accumulation of knowledge and skills of farmers, have wide ranging consequences in the long run. Accumulation of knowledge and skills of farmers are important production factors in agriculture. However, future development may be dependent on initial conditions or on special dynamics of learning and investments. This increases the complexity and uncertainty of agricultural development. Under some simplifying assumptions, however, complex path dependent processes of technical and agricultural change can be modelled without making the model and its results intractable or too difficult to understand.

The changes in land use, animal production and the use of production inputs, obtained from the DREMFIA model, are utilised in the nutrient transport model ICECREAM [Tattari et al. 2001] 
to evaluate field scale environmental impacts of different agricultural policies. Two catchments, which vary in their location and characteristics, have been selected for this study. This paper discusses the effort and the first experiences when connecting policy scenarios with impact modelling.

\section{METHODS}

\subsection{THE SECTOR MODEL}

The DREMFIA model is dynamic recursive and includes 17 production regions. The model provides effects of various agricultural policies on land use, animal production, farm investments and farmers' income. Endogenous investments in different production techniques are modelled using the concept of technology diffusion. Since the endogenous technical change and explicit sector level investments are rare in standard economic models, one may expect the DREMFIA model to yield impacts of agricultural policy changes different from those reported by traditional economic models and reasoning. One can compare the DREMFIA results, for example, with the results of Jensen \& Frandsen [2003].

In the DREMFIA model annual land use and production decisions from 1995 till 2020 are simulated by an optimisation model which maximises producer and consumer surplus subject to regional product balance and resource (land) constraints. Products and intermediate products may be transported between the regions. The optimisation model is a typical spatial price equilibrium model (see e.g. Cox \& Chavas [2001]), except that no explicit supply functions are specified (i.e. supply is a primal specification), and foreign trade activities are included in DREMFIA. Armington assumption, which is a common feature in international agricultural trade models but less common in one-country sector models, is used. Imported and domestic products are imperfect substitutes, i.e. endogenous prices of domestic and imported products are dependent. There are 18 different processed milk products and their regional processing activities in the model.

Technical change and investments, which imply evolution of farm size distribution, are modelled as a process of technology diffusion. Investments are dependent on economic conditions such as interest rates, prices, support, production quotas and other policy measures and regulations imposed on farmers. The model of technology diffusion follows the main lines of Soete \& Turner [1984].

Two crucial aspects about diffusion and adaptation behaviour are included: first, the profitability of the new technique, and second, the risk and uncertainty involved in adopting a new technique. The information about and likelihood of adoption of a new technique will grow as its use becomes wider spread.

To cover the first point, likelihood of adoption of a new technique $\left(f_{\beta \alpha}\right)$ is made proportional to the fractional rate of profit increase in moving from technique $\alpha$ to technique $\beta$, i.e. $f_{\beta \alpha}$ is proportional to $\left(r_{\beta}-r_{\alpha}\right) / r_{\alpha}$ where $r_{\alpha}$ is the rate of return for technique $\alpha$ and $r_{\beta}$ is the rate of return for technique $\beta$. The second point is modelled by letting $f_{\beta \alpha}$ be proportional to the ratio of the capital stock in the $\beta$ technique $\left(K_{\beta}\right)$ to the total capital stock $K$ (in a certain agricultural production line), i.e. $K_{\beta} / K$. The total investments to $\alpha$ technique, after some simplification, is

$$
I_{\alpha}=\sigma\left(Q_{\alpha}-w L_{\alpha}\right)+\eta\left(r_{\alpha}-r\right) K_{\alpha}
$$

where $\sigma$ is the savings rate (proportion of economic surplus re-invested in agriculture), $\eta$ is the farmers' propensity to invest in alternative techniques, $Q_{\alpha}$ is the total production linked revenue for technique $\alpha, w$ is a vector of input prices, $L_{\alpha}$ is a vector of variable production factors of technique $\alpha$, and $r$ is the average rate of return on all techniques.

The interpretation of this investment function is as follows. If $\eta$ were zero then (1) would show that the investment in the $\alpha$ technique would come entirely from the investable surplus generated by the $\alpha$ technique. For $\eta \neq 0$ the investment in the $\alpha$ technique will be greater or less than the first term, depending on whether the rate of return on the $\alpha$ technique is greater than the average rate of return on all techniques $(r)$. This seems reasonable. If a technique is highly profitable then it will tend to attract investment and conversely if it is relatively less profitable investment will decline. If there are no investments in $\alpha$ technique at some time period, the capital stock $K_{\alpha}$ decreases at the depreciation rate. To summarise, the investment function (1) is an attempt to model the behaviour of farmers whose motivation to invest is greater profitability but nevertheless will not adopt the most profitable technique immediately, because of uncertainty and other retardation factors.

The endogenous investments and technical change, as well as the recursive structure of DREMFIA model imply that the incentive for changes must affect production more than one year before significant changes in production may occur. Hence the DREMFIA model is designed to be used in 
evaluation of medium and long term effects of agricultural policy.

Endogenous investments determine animal and crop production volume in the long-term, but shortterm changes in crop production are constrained by flexibility constraints. The constraints are validated on the basis of average crop production data from 1990-2002. Consumption trends are given exogenously. Fertilisation and yield levels are dependent on crop and fertiliser prices through crop yield functions. Feeding of animals may change in the short-term within certain bounds imposed by fixed production factors and animal biology provided that nutrition requirements are fulfilled. Specific production functions are used to model the dependency between the average milk yield of dairy cows and the amount of the grain based feed stuffs used in feeding. The yield of dairy cows responds to price changes of milk and feed stuffs. Time series of the model outputs include number of animals, areas of different crops and feeding of animals. The detailed presentation of model and its parameters can be found in Lehtonen [2001, 2004].

The technology diffusion model has been validated to observed evolution of farm size distribution in 1995-2002. The overall model replicates very closely ex-post production in 1995-2002.

\subsection{THE CATCHMENT MODEL}

The ICECREAM model Tattari et al. [2001]; Bärlund and Tattari [2001], used for environmental impact assessment, is developed to simulate water, soil loss and phosphorus (P) and nitrogen (N) transport in the unsaturated soil of agricultural land. The model simulates on field scale but the model results have been aggregated using typical soil-crop-slope combinations to small catchment scale to describe transport from agricultural land [Rekolainen et al., 2002]. Special attention in ICECREAM development has been paid on including management practices such as various tillage methods, fertilisation practices and land use options like vegetative strips.

To assess the environmental impacts of the agricultural policy scenarios, the results of the field scale simulations with ICECREAM are up-scaled. The relevant soil-crop-slope combinations form a simulation matrix of 6 soil types, 11 crop types and 9 field slopes, i.e. 594 single simulations. These results are averages of annual sums of e.g. leached nitrate- $\mathrm{N}$ over the simulation period, here 10 years. The parameters to characterise soil properties and crop development are equal in both simulated areas but the meteorological conditions are typical for each region. The response to the results from the
DREMFIA model is gained weighing the ICECREAM matrix by the percentage of each soilcrop-slope combination in each catchment for each particular year.

\subsection{CATCHMENT AREAS}

The two catchments selected for this study vary in their location and characteristics. Yläneenjoki catchment is situated in the coastal plains of south-western Finland. Its total area is larger (227 $\mathrm{km}^{2}$ ) but its field percentage smaller $(35 \%)$ than of the Taipaleenjoki catchment $\left(27 \mathrm{~km}^{2} ; 50 \%\right)$, which is situated in eastern Finland. The main line of production in Yläneenjoki is spring cereals whereas in Taipaleenjoki it is dairy production, which also explains the higher share of grassland in this area. Yläneenjoki region, on the other hand, is strong in pork and poultry production. Yläneenjoki is one of the relatively best grain production areas in Finland. The yields of wheat and malting barley, in particular, are higher than average yields in Finland. Farms having dairy and beef cattle are of the same size in both Yläneenjoki and Taipaleenjoki areas, but pork and poultry farms in Yläneenjoki area are significantly larger and specialised than in Taipaleenjoki region.

\subsection{THE POLICY SCENARIOS}

Base-scenario follows Agenda 2000 reform (agreed in Berlin 1999; CEC [1999]) which is assumed to stay unchanged until 2020. It is assumed that producer price of milk would fall by 15\% in Finland until 2008 from the average producer price of 1999-2001 (35,3 c/litre). Hence the producer price of milk would be $30,01 \mathrm{c} /$ litre in 2008-2015 in Base -scenario. LFA-, environmental and national support, mainly paid per hectare of different crops, are assumed to stay at 2003 year level in 2004-2015.

Mid Term Review (MTR) -scenario, ranging up to year 2020, is a combination of EU Commission's agricultural policy reform proposal [CEC 2003] presented in January 22 2003, and the CAP reform agreed in June 2003. CAP-support, based on 2000-2002 historical production levels, is paid in a single farm payment each year.

Producer price of milk falls by $28 \%$ in the EU until 2009. In Finland such a change means that the average producer price of 1999-2001 (35,3 c/litre) reduces to $25,4 \mathrm{c} /$ litre in 2009 . The milk price cut is compensated by payments per quota ton. The payment goes up to 41 euros per ton (prior 5\% modulation) until 2008. 
An increase in LFA support is assumed. The increase of LFA support would be directed for milk and cattle farms. The support rate per bovine animal unit would increase linearly up to 300 euros per bovine animal until 2009. Overall this would mean a $50 \%$ increase in the total LFA support. National supports, paid per hectare of certain special crops and per animal, are kept at base scenario level.

Integrated rural and environmental policy (INT) -scenario is built on MTR-scenario in such a way that environmental concerns and labour in rural areas are of particular emphasis. This means that support for grass area is increased, and labour is supported by paying 3 euros per hour of work for farms which have bovine animals. CAP extensification premium is not de-coupled from production. LFA support is kept at the base scenario level. EU price level of agricultural products would be the same as in MTR scenario.

Free trade -scenario and full scale agricultural trade liberalisation (LIB) includes the most drastic changes. All agricultural support is transformed into an area based flat rate support which is the same for all crops and is de-coupled from production. This transformation would be complete in 2010. The total sum of agricultural support is decreased by $10 \%$ by year 2014. Prices of agricultural products in the EU are 5-20\% lower than in MTR and INT -scenarios.

\section{RESULTS AND DISCUSSION}

Let us briefly discuss the changes in production in the whole country level because that provides a major explanation for the changes in production in Yläneenjoki and Taipaleenjoki catchments. Production in both areas, reported in tables 1 and 2, is influenced by production in other areas because of balance between total supply and demand.

Milk production has a strong effect on land use in Finland. Dairy capital decreases drastically in INTand LIB-scenarios. The rate of return on investment decreases well below the general interest rate (assumed 5\% until 2020), which implies drastic downturn in investments. In INT -scenario the labour support, which should reinforce supply ceteris paribus, makes investments in large production units relatively less profitable and hence inhibits the development of competitive farm structures in the long-term. The decrease in investments and dairy capital is less drastic in MTR scenario because of increased LFA support for bovine animals. In any case supply of milk will gradually decrease in MTR scenario due to lower milk prices and de-coupled CAP payments. The decrease of beef supply is relatively larger than milk supply due to increasing milk yield and reducing dairy herd.

Agricultural policy changes have little effect on pig and poultry production, since relatively small changes are expected for pork and poultry sectors.

The development of dairy production in both Yläneenjoki and Taipaleenjoki areas are characterised by the same kind of development and drivers of development as in the whole country: dairy production decreases significantly in MTR-, INTand in LIB-scenarios because of low profitability of investments. Small dairy farms allocate land to set-aside instead of investing in dairy production.

Suckler cow numbers, however, increase in base scenario in both areas, especially in Taipaleenjoki area. This is due to considerable national support for grass area while beef prices and production linked supports keep up production. Grass area increases and grain area decreases significantly (from the 1995 level) in Taipaleenjoki region already in the base scenario until 2015. This is because Taipaleenjoki region becomes even more dominated by dairy production and grain production concentrates to more feasible regions.

In the MTR scenario suckler cow numbers at whole country level increase only slightly because increased LFA -support is outweighed by decoupled CAP support. However, in Taipaleenjoki region the number of suckler cows increases even in the MTR scenario because there is a strong incentive for extensive grass cultivation. The intensive dairy production is replaced by very extensive grass cultivation. This is a rational consequence of low milk price and decoupled CAP payments. In the LIB scenario the dairy herd declines drastically and set aside becomes the relatively most profitable use of land.

In Yläneenjoki region the milk production reduces only slightly in the MTR scenario because of lower feed costs compared to Taipaleenjoki area. Since Yläneenjoki area is one of the relatively best grain production areas in Finland, incentive for extensive grass cultivation is not as strong as in Taipaleenjoki area. In the MTR scenario, however, grain and grass areas decrease slightly in Yläneenjoki region while set aside areas increase up to $11 \%$ of the total area. In INT and LIB scenarios, where LFA support is lower than in MTR scenario, set aside areas are high in 2015. It is remarkable that even if the total grain area in Finland decreases drastically in the LIB scenario, grain area does not change much in the Yläneenjoki region. 
Table 1 Development of the number of animals [1000 heads] according to the 2001 survey and estimated by DREMFIA for the four scenarios BAS (Agenda 2000), MTR (Mid Term Review), INT (Integrated Policy) and LIB (Free Trade) in 2015.

\begin{tabular}{l|ccccc|ccccc}
\hline & \multicolumn{5}{|c|}{ Yläneenjoki } & \multicolumn{5}{c}{ Taipaleenjoki } \\
\hline & 2001 & BAS & MTR & INT & LIB & 2001 & BAS & MTR & INT & LIB \\
\hline Dairy cows & 1,56 & 1,30 & 1,13 & 0,74 & 0,58 & 3,0 & 2,57 & 1,41 & 1,13 & 0,70 \\
Suckler & 0,40 & 0,46 & 0,17 & 0,11 & 0,09 & 0,07 & 0,25 & 0,14 & 0,25 & 0,02 \\
cows & & & & & & & & & & \\
Sows & 6,65 & 3,15 & 4,26 & 3,47 & 1,91 & 0,18 & 0,04 & 0,04 & 0,04 & 0,05 \\
Pigs & 39,1 & 21,85 & 29,55 & 24,12 & 13,27 & 1,08 & 0,29 & 0,29 & 0,29 & 0,35 \\
Hens & 246,8 & 171,5 & 271,2 & 228,9 & 117,5 & 0,85 & 0,22 & 0,22 & 0,22 & 1,07 \\
Other & 519,7 & 1022,6 & 704,5 & 773,3 & 346,3 & 0 & 0 & 0 & 0 & 0
\end{tabular}

Table 2 Distribution of crops [\% of cultivated area] simulated by ICECREAM according to the 1995 survey and estimated by DREMFIA for the four scenarios BAS (Agenda 2000), MTR (Mid Term Review), INT (Integrated Policy) and LIB (Free Trade) in 2015.

\begin{tabular}{l|ccccc|ccccc}
\hline & \multicolumn{7}{|c|}{ Yläneenjoki } & \multicolumn{5}{c}{ Taipaleenjoki } \\
\hline & 1995 & BAS & MTR & INT & LIB & 1995 & BAS & MTR & INT & LIB \\
\hline oats & 17 & 22 & 27 & 27 & 29 & 27 & 31 & 13 & 9.8 & 1.9 \\
barley & 37 & 57 & 45 & 40 & 39 & 14 & 0.68 & 0.37 & 0.11 & 0.20 \\
s_wheat & 11 & 2.4 & 2.8 & 2.3 & 3.6 & 1.9 & 0.013 & 0.013 & 0.013 & 0.013 \\
oilseeds & 4.1 & 1.0 & 1.4 & 0.97 & 1.8 & 0.95 & 0.0063 & 0.0063 & 0.0063 & 0.0063 \\
w_wheat & 4.6 & 1.1 & 1.2 & 1.0 & 1.6 & 0 & 0 & 0 & 0 & 0 \\
rye & 4.2 & 0.97 & 1.1 & 0.93 & 1.5 & 1.8 & 0.012 & 0.012 & 0.012 & 0.012 \\
s_beet & 2.3 & 0.54 & 0.62 & 0.51 & 0.80 & 0 & 0 & 0 & 0 & 0 \\
potato & 1.4 & 0.31 & 0.36 & 0.30 & 0.47 & 0.72 & 0.0048 & 0.0048 & 0.0048 & 0.0048 \\
grass & 7.7 & 6.4 & 4.8 & 3.5 & 4.8 & 45 & 64 & 82 & 85 & 39 \\
g_fallow & 8.3 & 4.3 & 11 & 19 & 14 & 3.9 & 4.4 & 4.4 & 4.4 & 58 \\
b_fallow & 1.0 & 0.23 & 0.27 & 0.22 & 0.34 & 3.4 & 0.023 & 0.023 & 0.023 & 0.27 \\
\hline s_wheat: spring wheat; $w$ w wheat: winter wheat; s_beet: sugar beet; g_fallow: green fallow; b_fallow: bare fallow
\end{tabular}

Figure 1 Simulated change in average annual sum of soluble (DPr, a) and sediment bound (PP, b) P in surface runoff and nitrate- $\mathrm{N}$ in percolation from root zone $\left(\right.$ perc $\mathrm{NO}_{3}, \mathrm{c}$ ) from arable land in 2015 relative to the situation in 1995 in Yläneenjoki (YLA) and Taipaleenjoki (TAI) catchments.
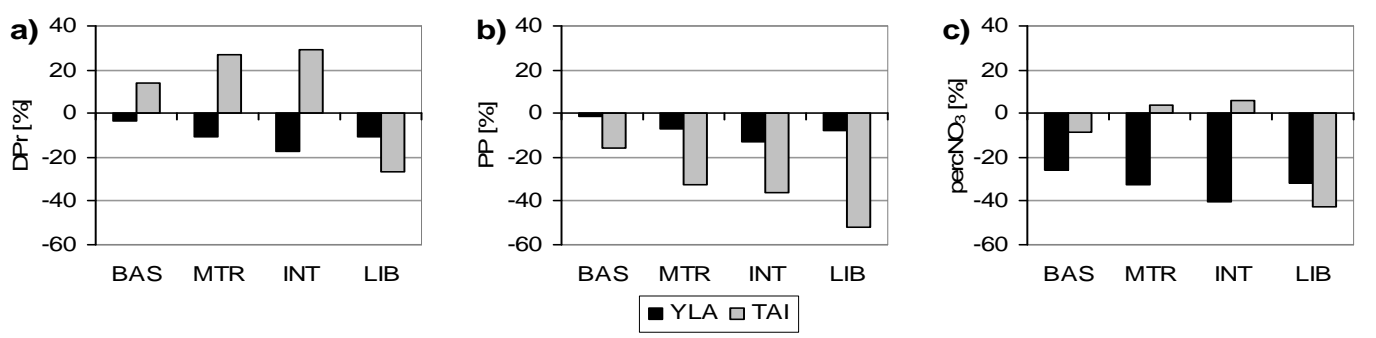

According to ICECREAM model, the change in DPr and PP due to the base scenario is close to no change in Yläneenjoki region. All other scenarios would lead to a small reduction of both variables. For DPr this is due to reduction of grass and increase of green fallow and for PP the main reason is the reduction of bare fallow and winter cereals in the catchment, both land use types having relatively high PP loss values. Grass is the only crop receiving surface applied fertilisation and thus a decrease in the grass area reduces DPr losses effectively The rather high reduction of perc $\mathrm{NO}_{3}$ can be explained by a smaller area of oilseeds and winter cereals. Both crop types have rather high $\mathrm{N}$ fertilisation compared to simulated crop uptake, which explains losses in percolated water.

In Taipaleenjoki region the relative change in $\mathrm{P}$ leaching is higher than in Yläneenjoki and for DPr an increase is indicated for all scenarios except LIB. For DPr the main reason would be the larger area under grass in 2015 compared to 1995. The DPr decrease under the LIB scenario is explained by the extremely high increase in green fallow area. The change in grass and green fallow area explains also the reduction of PP for all scenarios. The results for percNO $\mathrm{N}_{3}$ for MTR and INT scenarios can be interpreted as no change. The reduction for the other scenarios is a combination of an increase in the area of oats (BAS) and green fallow with very low nitrate leaching and reduced area of 
oilseeds and winter cereals with high nitrate leaching potential.

The Yläneenjoki area is more susceptible to eutrophication due to natural conditions and loading history but it has to be investigated what the predicted change would mean in Taipaleenjoki conditions over a longer time period. Therefore, future analysis on the effect of predicted actual nutrient load change on variables describing eutrophication (e.g. Secchi depth) is needed.

\section{CONCLUSIONS}

Large reductions in milk price and a simultaneous de-coupling of CAP payments are likely to cut dairy investments considerably. This would cease the ongoing structural change, farm size growth and production specialisation on Finnish dairy farms ${ }^{1}$. Instead, many dairy farms would refrain from investment and allocate land to set-aside. Milk and especially beef production volumes would decrease considerably in the long-term. Also grain area would decrease slightly. De-coupling CAP-support, however, would have only marginal effects on pork and poultry production.

The coupled use of the economic model DREMFIA and the environmental model ICECREAM enabled to test the effect of four different agricultural policy scenarios on nutrient leaching in two Finnish catchments with varying characteristics. The relative change in nutrient leaching was dependent on the policy scenario applied, the nutrient leaching variable studied and on the catchment chosen. In the Yläneenjoki catchment in southwestern Finland a reduction of all variables presented would be expected, whereas in Taipaleenjoki in eastern Finland especially soluble $\mathrm{P}$ in surface runoff might be increasing even if product prices were reduced and subsidies were de-coupled from production. This challenges a common view that lower prices and decoupled subsidies always imply less environmental harm. In order to utilise the results in policy dialogue, further refinement of the method is needed in order to quantify the effect in each particular area and to link the nutrient load from agriculture to the eutrophication potential.

\section{ACKNOWLEDGEMENTS}

\footnotetext{
${ }^{1}$ Such effects are not taken into account in standard economic tools. For example, Jensen \& Frandsen 2003 report no change in Finnish dairy production, and a remarkable increase in beef production, due to 2003 CAP reform.
}

The financial support of the SUSAGFU project through the Academy of Finland (contract 76724) is gratefully acknowledged.

\section{REFERENCES}

Bärlund I. and Tattari S., Ranking of parameters on the basis of their contribution to model uncertainty. Ecol. Modell., 142, 11-23, 2001.

CEC, http://europa.eu.int/comm/ agenda2000/index_en.htm, 1999.

CEC, http://europa.eu.int/comm/ agriculture/ mtr/index_en.htm, 2003.

Cox T.L. and Chavas J.-P., An interregional analysis of price discrimination and domestic policy reform in the US dairy sector. Am. J. Agric. Econ., 83(1), 89-106, 2001.

Heckelei, T., Witzke, P. and Henrichsmeyer, W., Agricultural Sector Modelling and Policy Information Systems. In Proceedings of the $65^{\text {th }}$ European Seminar of the European Association of the Agricultural Economics (EAAE), March 29-31, Bonn, Germany 2000, 2001.

Jensen, H.G. and Frandsen, S.E., Impacts of the Eastern European Accession and the 2003-reform of the CAP. FOI Working paper no. 11/2002. Danish Research Institute of Food Economics, 2003.

Lehtonen H., Principles, structure and application of dynamic regional sector model of Finnish agriculture. $\mathrm{PhD}$ thesis, Systems Analysis Laboratory, Helsinki University of Technology. Agrifood Research Finland, Economic Research (MTTL) Publ. 98. Helsinki, 2001

Lehtonen, H., Impacts of de-coupling agricultural support on dairy investments and milk production volume in Finland. Forthcoming in Acta Agriculturae Scandinavica, Section C: Food Economics, 2004.

Rekolainen S., Salt C.A., Bärlund I., Tattari S. and Culligan-Dunsmore M., Impacts of the management of radioactively contaminated land on soil and phosphorus losses in Finland and Scotland. Water, Air, Soil Pollut., 139, 115-136, 2002.

Soete, L. \& Turner, R, Technology diffusion and the rate of technical change. The Economic Journal. pp. 612-623. September 1984.

Tattari S., Bärlund I., Rekolainen S., Posch M., Siimes K., Tuhkanen H.-R. and YliHalla M., Modelling sediment yield and phosphorus transport in Finnish clayey 
soils. Trans. ASAE, 44(2), 297-307, 2001. 